\title{
LIVROS\& REDES
}

\section{Coisas da Amazônia}

Things of the Amazon

\author{
Cristina Scheibe Wolff \\ Servidão João Chagas, 194 \\ 88063-542 Florianópolis — SC Brasil \\ cristiwolff@terra.com.br
}

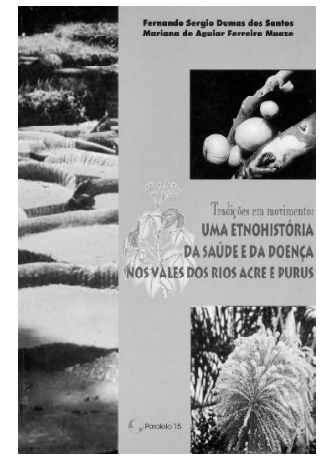

Fernando Sergio

Dumas dos Santos

e Mariana de Aguiar

Ferreira Muaze

Tradiçôes em

movimento: uma etnobistória da saúde $e$ da doença nos vales dos rios Acre e Purus. Brasília, Paralelo 15, 2002, 170p.
$\mathrm{U}$ $\mathrm{m}$ amigo de longa data, pesquisador da geografia amazônica, dizia em certa ocasião que uma das características da produção acadêmica sobre a Amazônia é que cada um de nós, ao escrever sobre a região, acha-se na obrigação de explicar cada termo tirado daquela realidade tida como tão distante da nossa. Preocupamo-nos em explicar ao público, por certo totalmente alheio ao que ocorre na floresta, palavras e noções como 'colocação', 'varadouro', 'remoso' ou 'volta da estrada' (de seringa). Cada uma delas merece explicação, notas de rodapé, às vezes até desenhos e fotografias. Muitos são os trabalhos que apresentam glossários, e em minhas buscas em bibliotecas encontrei até um "dicionário de cousas da Amazônia" (Moraes, 1931).

O problema de estar sempre explicando essas coisas diferentes, descrevendo as viagens que fazemos na Amazônia, é que muitas vezes acabamos parando nas descrições. A Amazônia permanece, no imaginário, uma região desconhecida e recoberta por brumas misteriosas. Como mostra o brilhante livro de Neide Godim, A invenção da Amazônia (1994), o imaginário sobre a região fundamenta-se na literatura de viagens. A Amazônia representa o desconhecido e, ao mesmo tempo, o lugar onde poderíamos encontrar uma natureza intocada (Diegues, 1996). O livro Tradições em movimento: uma etnohistória da saúde e da doença nos vales dos rios Acre e Purus, de Fernando S. D. dos Santos e Mariana de A. Muaze, dialoga com este problema.

O livro é resultado de uma viagem, e portanto não deixa de trazer essa matriz em evidência. A viagem de 45 dias pelos rios Acre e Purus fez parte do projeto Revisitando a Amazônia de Carlos Chagas: da Borracha à Biodiversidade e teve como objetivo pesquisar as condições de vida e de saúde das populações amazônicas visitadas pelo médico sanitarista Carlos Chagas entre 1912 e 1913 (p. 9). Desse projeto, levado a efeito por extensa equipe da Fundação Osvaldo Cruz, nasceu a pesquisa 'Tradições de uso de plantas medicinais na Amazônia'. Ao longo da viagem foram realizadas entrevistas orais com pessoas indicadas nas comunidades como conhecedoras das ervas medicinais e dos processos de cura. Segundo os autores, a forma 
de fazer a pesquisa, valorizando os "modos de fazer" e as experiências das populações ribeirinhas, "... atua não somente como mecanismo de conhecimento histórico e preservação desta cultura, mas também como tentativa de valorizar e de recuperar experiências até hoje confinadas" (p. 15).

A proposta do livro é mesmo uma espécie de descrição de viagem, embora não somente em uma dimensão espacial, mas também na dimensão do tempo, acompanhando o vaivém das memórias dos entrevistados. Os autores buscam situar a cultura local na história por meio da leitura de várias obras sobre a região, comparando-as muitas vezes com as memórias apresentadas pelos entrevistados. No primeiro capítulo, 'A permanência da cultura do barracão', percebe-se assim, em certo sentido, uma espécie de nostalgia do barracão, dos tempos áureos da produção da borracha, acompanhando as saudades expressas pelos entrevistados, como o sr. José Cândido: "Minha vida, mocidade toda foi no seringal. Toda, toda, toda. Minha vida eu gastei toda no seringal. Mas a vida é assim mesmo" (p. 66).

Nesse capítulo os autores destacam a presença das populações indígenas que permaneceram como trabalhadoras dos seringais e fazem uma descrição da ocupação da região em três tempos: o tempo dos brabos, o tempo dos arigós e o tempo dos soldados da borracha. Tal periodização é centrada portanto na figura dos migrantes nordestinos que foram para as regiões dos altos rios amazônicos para explorar a borracha nativa. Os 'brabos' eram os migrantes que chegavam no tempo do auge do preço da borracha no mercado mundial. Vinham em busca da 'riqueza fácil' prometida pelos arregimentadores de mão-de-obra e fugidos das grandes secas do Nordeste. Como animais 'brabos', precisavam ser 'amansados' na lida da floresta por meio da disciplina imposta pelos patrões nos seringais. Os 'arigós' seriam os seringueiros estabelecidos com suas famílias a partir do início da década de 1910, quando o preço da borracha natural começou a declinar no mercado mundial. O terceiro momento foi aquele em que os migrantes nordestinos mais uma vez foram arregimentados para a 'batalha da borracha', mercadoria estratégica para o esforço aliadado de guerra, especialmente com a invasão da Malásia pelo Japão em 1942.

Para articular todos esses momentos, os autores utilizam a idéia de uma 'cultura do barracão'. O barracão — lá vou eu explicando - era a casa comercial e residência do 'patrão', sede do seringal. Era ali que o seringueiro trocava sua borracha pelas mercadorias necessárias à sobrevivência. Também nele se encontrava alguma assistência na doença, sob a forma de remédios e sociabilidade. A idéia de cultura do barracão, já desenvolvida anteriormente por Fernando Dumas dos Santos em artigo, parece apontar para uma espécie de 'mentalidade', ou seja, uma forma de entender o mundo e estruturar as relações sociais que perdura entre a população ribeirinha, apesar das transformações em seu modo de vida, na economia regional e mesmo a despeito do quase desaparecimento dos barracões. Por isso a saudade.

Nesse ponto gostaria de provocar um pouco mais a discussão com meus colegas historiadores/viajantes da Amazônia. Nas entrevistas que fiz alguns anos antes na região do Alto Juruá, também senti em muitos momentos essa saudade do barracão. Mariana Pantoja Franco (1994) mostrou igualmente, em artigo muito bem escrito e embasado em trabalho etnográfico de anos na região, a 'fetichização' das mercadorias nas florestas. Ou seja, que as relações entre patrões e fregueses, na memória que aparece nas 
entrevistas, costumam ser um tanto romantizadas. São pensadas como trocas de favores, nas quais os fregueses (seringueiros) trabalhavam e vendiam sua borracha exclusivamente para aquele patrão, enquanto que este retribuía a lealdade adiantando mercadorias, concedendo crédito, prestando auxílio em casos de doença, morte e outras situações. Em lugar tão abandonado, a existência do patrão significava ter a quem recorrer, ainda que se corresse o risco de uma ajuda não eficiente.

Entretanto os autores fazem um salto temporal muito grande entre a 'batalha da borracha' e a atualidade. Nesse meio tempo muito mudou na Amazônia: todo o desenvolvimento da atividade de extração do látex patrocinada por financiamentos e subsídios governamentais nos anos da ditadura militar; a nova e estrondosa queda do preço da borracha, agora no mercado local; o fim dos subsídios nos anos 1990; o processo de derrubada de muitos seringais para a implantação de pastagens; o surgimento do movimento dos seringueiros, os encontros dos Povos da Floresta.

É certo que esses acontecimentos atingiram diferentemente as pessoas na Amazônia, mas foi justamente o vale do rio Acre o berço dos Empates e do movimento dos seringueiros. Foi lá que Chico Mendes conseguiu, junto com outros líderes sindicalistas e principalmente junto com seringueiros e seringueiras, articular os novos ideais políticos do ambientalismo aos interesses dos seringueiros. Mostrou a indissociabilidade entre a sobrevivência da floresta e o modo de vida das populações de seringueiros, indígenas, ribeirinhos e outros povos amazônicos (Almeida, 1992; Alegretti, 1994; Gonçalves, 1998). Neste processo o barracão foi derrubado e reconstruído, agora em outras bases, como cooperativa.

É claro que uma cultura dessas não se altera de uma hora para outra, especialmente se nosso termômetro é constituído especialmente de depoimentos orais de pessoas relativamente idosas. Mas hoje, quando as reservas extrativistas e outras experiências tentam negar os patrões e construir uma outra territorialidade, uma outra cultura, uma outra história, qual o significado de reafirmar a permanência da cultura do barracão?

Ao revisitarem os rios Acre e Purus, os pesquisadores da Fundação Osvaldo Cruz procuravam averiguar as condições de vida e saúde das populações que lá residem. Encontraram a sobrevivência de práticas de cura ligadas ao uso de ervas medicinais e rezas, práticas estas que foram as formas de enfrentar as doenças encontradas entre a população amazônica. No segundo capítulo do livro, 'Doenças do corpo e doenças do espírito', os autores procuram inventariar as principais doenças que aparecem nas falas dos depoentes e nos exames realizados pela equipe médica da expedição. Buscam uma tipologia nativa das doenças e dos tratamentos empregados. É assim que chegam à divisão entre doenças do corpo e doenças do espírito do título do livro, embora ao longo do capítulo fique claro que os depoentes se referem a 'doenças de reza' (tratadas por rezadores) e ‘doenças de remédio’ (tratadas com remédios de farmácia ou fitoterápicos, conforme a disponibilidade e gravidade). As doenças de reza não são necessariamente doenças do espírito, mas, segundo a tradição trazida do Nordeste, os males cujas palavras proferidas por um rezador, acompanhadas às vezes de massagens, chás e rituais podem curar. Doenças como erizipela, vermelha, cobreiro, peito aberto, espinhela caída, paralisia, dor de dente, 
engasgado, dor na vista e espremedeira (dor de barriga) são assim tratadas por homens ou mulheres que aprenderam as rezas com pessoas mais velhas.

"Estamos diante de um somatório de saberes, oriundos de formas culturais distintas, estabelecidos em temporalidades diferenciadas e que gerou um novo saber, forjado desde as próprias práticas da população, nas relações entre as pessoas, na organização socioprodutiva da comunidade, nas maneiras de viver dos grupos sociais" (p. 74). A análise da importância dos rezadores e das rezas é bem-feita e utiliza-se basicamente das entrevistas realizadas e de alguma literatura, já bastante antiga, sobre o folclore nordestino e amazônico. A vastidão e dispersão do que se produz sobre a Amazônia certamente impediu os autores de dialogarem com outros estudos recentes sobre este tema (Barbin, 1999; Araújo, 1998, Cunha et al., 2002, entre outros)

Ao falarem das 'doenças de remédio’ aparece mais claramente a comparação, extremamente interessante, entre as doenças encontradas por Carlos Chagas em 1912 e pela expedição de 1997. A malária, a hanseníase, a febre amarela, a leishmaniose parecem manter-se como doenças importantes ainda hoje. A hepatite, apesar de não ter sido citada por Carlos Chagas, possivelmente já naquela época era importante e hoje ainda é endêmica na região, especialmente aliada à malária — já que ambas atacam o fígado das vítimas. A conclusão dos autores é estarrecedora e merece atenção das autoridades, não somente locais, mas também nacionais: “... percebemos uma continuidade de todos os problemas apontados em 1913. ... Atualmente, à antiga problemática somam-se outras moléstias, descritas como decorrentes da urbanização e, portanto, de aparecimento recente, mas que já inspiraram um grande medo na população, entre elas a meningite, a cirrose, as cardiopatias e a Aids" (p. 108).

Apesar de todas as transformações vividas por essas populações, as condições de acesso à saúde e educação são bastante precárias. Esse estudo tem o mérito de apontar tais condições e de não fazer um julgamento apressado a respeito delas, já que não se trata de simplesmente 'incluir' as pessoas em um sistema como o que (não) funciona nos centros urbanos, e sim de pensar alternativas em conjunto com a população local, que possam ser adequadas às suas aspirações e culturas.

O terceiro capítulo do livro, 'As atuais tradições de uso de plantas medicinais', recorre às entrevistas orais para uma descrição dos modos como atualmente são utilizadas as plantas medicinais, dando mais um passo nessa direção, que inclui o respeito às populações como sábias gestoras dos recursos florísticos. Enfatiza o caráter de improvisação que muitas vezes acompanhou o uso dos remédios fitoterápicos, causada pela necessidade extrema diante da doença. Chama a atenção também para a utilização atual da tradição por organismos como as Pastorais da Criança e da Terra - ligadas à Igreja Católica —, e talvez devêssemos incluir aí outras organizações não-governamentais e mesmo prefeituras, estas por meio dos chamados 'agentes de saúde'. Segundo os autores "O trabalho das pastorais é bem recebido pelas comunidades porque se pauta em dois parâmetros que há muito possuem grande legitimidade entre as populações da floresta: os remédios caseiros e a solidariedade" (p. 121). 
O capítulo descreve as diferentes maneiras pelas quais são usadas as plantas medicinais, como infusões, sumos, pós, compressas, fricções, xaropes e ungüentos, e como as formas de preparo se relacionam com as indicações terapêuticas. Também mostra a importância dada a ingredientes não-vegetais, como a presa do porquinho-do-mato ou o fígado da arraia. A tradição é invocada neste capítulo, especialmente os modos de fazer com raiz nordestina, no sentido de possibilitar a análise das maneiras de preparar, dosar e improvisar os remédios. É também nos saberes tradicionais e nas similaridades entre as diversas plantas que curadoras e curadores vão buscar os cuidados com cada planta: plantas amargosas não devem ser dadas para criancinhas ou mulheres grávidas; certos vapores não devem atingir os olhos. Se a improvisação aparece em muitos momentos, ela não é simplesmente invenção, e sim a utilização do novo de maneiras conhecidas. Demonstrase não somente o desespero perante a doença, mas um profundo conhecimento baseado na experiência e em uma arguta observação da floresta.

Este livro, de leitura agradável e instigante, constitui uma importante colaboração para a uma história das populações amazônicas partindo de seus saberes e de sua vida. Se por vezes não evoca os trabalhos realizados em outras partes sobre temas correlatos, por outro lado valoriza o cotidiano e a experiência de mulheres e homens no seu viver. Também contribui para pensarmos sobre a importância dessas populações, consideradas tradicionais, para a sobrevivência da floresta e do saber sobre a flora, a fauna, o solo, os ambientes e seus usos. E nos faz pensar sobre os direitos desses homens e mulheres que, sabendo tanto, nunca se negaram a dividir com todos os seus conhecimentos, fundamentais para a cura de tantas doenças e para a preservação da vida no nosso planeta.

\section{REFERÊNCIAS BIBLIOGRÁFICAS}

Alegretti, Mary

1994

Almeida, Mauro William Barbosa de

1992

Antonacci, Maria

Antonieta

1994

Araújo, Maria Gabriela Jahnel de 1998

Barbin Jr. , Hélio 1999
'Reservas extrativistas: parâmetros para uma política de desenvolvimento sustentável na Amazônia'. Em Arnt, Ricardo (org.). O destino da floresta: reservas extrativistas e desenvolvimento sustentável na Amazônia.

Rio de Janeiro, RelumeDumarám, pp. 17-48.

Rubber tappers of the upper Jurua river, Brazil. The making of a Forest Peasant Economy. Dissertação de doutorado.

Cambridge, Universidade de Cambridge.

'Cultura, trabalho, meio ambiente: estratégias de "empate" no Acre'.

Revista Brasileira de História, vol. 14, no 28, pp. 247-67.

Entre almas, encantos e cipó. Dissertação de mestrado em antropologia, Universidade de Campinas (Unicamp), Campinas. (mimeo.)

Do feitiço à malária: uma etnografia do sistema de saúde na Reserva Extrativista do Alto Juruá - Acre. Dissertação de mestrado em antropologia social, Universidade Federal de Santa Catarina, Florianópolis. (mimeo.) 
Carneiro da Cunha, Manuela et al. (orgs.) 2002

Diegues, Antônio Carlos 1996

Franco, Mariana Pantoja 1994

Godim, Neide 1994

Gonçalves, Carlos Walter Porto 1998

Moraes, Raymundo 1931
Enciclopédia da floresta. O Alto Juruá: práticas e conbecimentos das populações. São Paulo, Companhia das Letras.

O mito moderno da natureza intocada. São Paulo, Hucitec.

'Seringueiros e cooperativismo: o fetichismo das mercadorias nos seringais do Alto Juruá'. Em L. Medeiros et al. (org.). Assentamentos rurais: uma visão multidisciplinar. São Paulo, Unesp, pp. 187-203.

A invenção da Amazônia.

São Paulo, Marco Zero.

Geografando. Nos varadouros do mundo (da territorialidade seringalista à territorialidade seringueira: do seringal à reserva extrativista).

Tese de doutoramento, Universidade Federal do Rio de Janeiro. (mimeo.)

O meu dicionário de cousas da Amazônia. 2 vols.

Rio de Janeiro, Alba. 